\title{
Relation between nutritional requirements and susceptibilities to antibiotics of strains of Neisseria gonorrhoeae from pharyngeal and anogenital sites
}

\author{
M C ANSINK-SCHIPPER, * B VAN KLINGEREN, † H HUIKESHOVEN,* \\ R WOUDSTRA,* AND M DESSENS-KROON† \\ From the *Municipal Health Service, Amsterdam and the $\uparrow$ National Institute of Public Health, Bilthoven, \\ The Netherlands
}

SUMMARY Auxotyping and antibiotic susceptibility testing was carried out on 100 consecutive isolates of non-penicillinase producing strains of Neisseria gonorrhoeae (non-PPNG) taken on the same occasion from throat and anogenital sites, 100 non-PPNG strains isolated from the throat only, and 100 non-PPNG strains from anogenital sites only. Non-requiring, non-requiring and phenylalanine inhibited, proline requiring, amino acid group requiring, and arginine requiring auxotypes predominated in all groups of patients. Strains of the arginine requiring type found in anogenital sites tended to have additional requirements. The auxotypes and susceptibility to antibiotics of 93 of the 100 paired cultures from the throat and anogenital sites were identical. There appeared to be a slight preponderance of moderately susceptible strains in isolates from the throat. A strong correlation was found between nutritional requirements and sensitivity to antibiotics. Auxotypes of and minimum inhibitory concentrations (MICs) for $N$ gonorrhoeae isolated from the throat were mostly the same as the auxotypes of and MICs for strains that were circulating during the study period in Amsterdam.

\section{Introduction}

Several authors have stated that the treatment usually given to patients with urogenital gonorrhoea was often not effective against oropharyngeal infection. ${ }^{1-3}$ The findings of Catlin and Pace indicated that gonococci of various auxotypes differed in their ability to colonise the oropharynx successfully. The percentage of strains moderately resistant to penicillin was higher in isolates from the oropharynx than in those from anogenital sites, ${ }^{4}$ a finding confirmed by Janda. ${ }^{5}$

In the study reported here isolates from the throat were compared with those from anogenital sites to find out whether the commonly persistent infections of the throat with Neisseria gonorrhoeae after treatment are due to strains of a particular auxotype or strains relatively resistant to antibiotics, or both. ${ }^{67}$

Address for reprints: Dr M C Ansink-Schipper, Municipal Health Service, P O Box 20244, 1000 HE Amsterdam, The Netherlands

Accepted for publication 22 June 1984

\section{Patients and methods}

COLLECTION OF GONOCOCCI

From April 1982 to October 1983 we cultured 340 strains of $N$ gonorrhoeae from 316 patients with uncomplicated gonorrhoea. The patients were from two groups: 292 attended the two sexually transmitted disease (STD) clinics of the public health service (Heads: G A J de Koning and D Tio) and 24 were patients of general practitioners and dermatologists in Amsterdam.

The strains selected were consecutive isolates as follows: 100 non-penicillinase producing $N$ gonorrhoeae strains (non-PPNG) isolated from throats and anogenital sites of patients with concomitant infection at both sites, 100 non-PPNG strains isolated exclusively from the throats of patients with throat infections only, and 100 nonPPNG strains isolated only from anogenital sites of patients with anogenital infections only. Of 40 penicillinase producing strains of $N$ gonorrhoeae (PPNG), 14 were isolated exclusively from the throat and 26 from the throat and anogenital sites. 
ISOLATION, IDENTIFICATION, AND

NUTRITIONAL REQUIREMENTS OF GONOCOCCI

Isolation, identification, and auxanographic typing of all strains were carried out as described elsewhere. ${ }^{8}$

\section{MEASUREMENT OF BACTERIAL RESISTANCE TO DRUGS}

The minimum inhibitory concentrations (MICs) of penicillin $G$, tetracycline, erythromycin, spectinomycin, cefuroxime, and thiamphenicol were measured by the agar dilution technique as described earlier. ${ }^{9}$ The MIC was defined as the lowest concentration of antibiotics that allowed the growth of no more than one visible colony after incubation for 24 hours.

\section{AMINOPEPTIDASE ACTIVITY}

Aminopeptidase activity was measured by the procedure described by Hoke and Vedros. ${ }^{10}$

\section{Results}

\section{AUXOTYPES}

Table I shows that 93 of the 100 patients with throat and anogenital infections had isolates with the same auxotype and the same susceptibility to the antibiotics tested. Table II shows the different auxotypes from the two sites in the remaining seven patients.

Of the 100 non-PPNG isolates from the throats of those with throat and anogenital infections, the 100 non-PPNG isolates from those with throat infections only, and the 100 non-PPNG isolates from those with anogenital infections only, 19, 24, and 31
TABLE I Auxotypes of isolates of $N$ gonorrhoeae from the throats of 93 patients with identical isolates from anogenital sites

\begin{tabular}{ll}
\hline Auxotype & $\begin{array}{l}\text { No of } \\
\text { isolates }\end{array}$ \\
\hline Non-requiring (NR) & 18 \\
Non-requiring inhibited by phenylalanine (NR Pheni) & 11 \\
Proline requiring (Pro-) & 21 \\
Arginine requiring (Arg-) & 5 \\
Arginine and amino acid group requiring (Arg- Amac-) & 6 \\
Amino acid group requiring (Amac-) & 21 \\
Other requirements & 11 \\
Total & 93 \\
\hline
\end{tabular}

respectively were non-requiring; 11,8 , and 7 were non-requiring and inhibited by phenylalanine; 22,20 , and 16 required proline; and 22,12 , and 18 required the amino acid group (tables I to III).

Of the 40 PPNG strains isolated from the throats of those with throat infections only and throat and anogenital infections in the same period, 18 were non-requiring and inhibited by phenylalanine, 18 required proline, two required amino acids, and two had other requirements.

Five of the 100 throat isolates from patients with throat and anogenital infections required arginine and 10 required arginine and other amino acids. Four of the latter strains were from the group of seven patients with different isolates from throat and anogenital sites (see tables I and II). In the isolates from patients with throat infections only, eight required arginine and eight required arginine and the amino acid group. In the patients with anogenital infection only these auxotypes were represented by three and four strains respectively (see table III). Twenty one other auxotypes were distinguishable, 11

TABLE II Minimum inhibitory concentrations (MICs) of five antibiotics to strains from seven patients with different auxotypes for concomitant throat and anogenital infections

\begin{tabular}{|c|c|c|c|c|c|c|c|}
\hline \multirow{3}{*}{$\frac{\text { Case No }}{1}$} & \multicolumn{2}{|c|}{ Auxotypes of strains from: } & \multicolumn{5}{|c|}{ MICs for strains isolated from throats (and anogenital sites) of: } \\
\hline & Throat & Anogenital sites & $\begin{array}{l}\text { Penicillin } \\
(I U / \mathrm{ml})\end{array}$ & $\begin{array}{l}\text { Tetracycline } \\
(\mu \mathrm{g} / \mathrm{ml})\end{array}$ & $\begin{array}{l}\text { Erythromycin } \\
(\mu \mathrm{g} / \mathrm{ml})\end{array}$ & $\begin{array}{l}\text { Cefuroxime } \\
(\mu \mathrm{g} / \mathrm{ml})\end{array}$ & $\begin{array}{l}\text { Thiamphenicol } \\
(\mu \mathrm{g} / \mathrm{ml})\end{array}$ \\
\hline & Arg - Amac- & Pro- Hyx- Ur- & $0 \cdot 25 \quad(0 \cdot 5)$ & $1 \quad(2)$ & $0.5 \quad(1)$ & $0.03 \quad(0.12)$ & (2) \\
\hline 2 & Arg- Amac- & Pro- Hyx- Ur- & $0 \cdot 12(0 \cdot 5)$ & $1 \quad(2)$ & $0 \cdot 25(1)$ & $0.015(0 \cdot 12)$ & (1) \\
\hline 3 & Arg- Amac- & Pro- Arg- & $0.12(0.015)$ & $1 \quad(1)$ & $0.5 \quad(0 \cdot 12)$ & $0.015(0.015)$ & $0.5 \quad(0.25)$ \\
\hline 4 & NR & Pro-Amac- & $0.015(0 \cdot 5)$ & 1 (4) & $0.5 \quad(2)$ & $0.015(0.12)$ & $0.25(2)$ \\
\hline 5 & Pro- & NR & $0.015(0.25)$ & $0.5(0.5)$ & $0 \cdot 25(1)$ & $0 \cdot 015(0 \cdot 12)$ & $0 \cdot 25(0 \cdot 5)$ \\
\hline 6 & Arg- Amac- & Amac- & $0.12 \quad(0.06)$ & $1 \quad(0 \cdot 25)$ & $(0 \cdot 12)$ & $0.06 \quad(0.03)$ & $0.5 \quad(0.5)$ \\
\hline 7 & Amac- & NR & $0.015(0.015)$ & $0 \cdot 25(0.25)$ & (1) & $0.015(0.015)$ & $0.25(0.25)$ \\
\hline
\end{tabular}

Arg- = arginine requiring; Amac $-=$ amino acid group requiring; $\mathrm{NR}=$ non-requiring; Pro-- = proline requiring; Hyx $-=$ hypoxanthine requiring; $\mathrm{Ur}-=$ uracil requiring. 
TABLE III Auxotypes of 100 strains of $N$ gonorrhoeae isolated during April 1982 to October 1983 from the throat only and 100 strains isolated from anogenital sites only in the same period

\begin{tabular}{lcc}
\hline Auxotypes & $\begin{array}{c}\text { Throat } \\
\text { only }\end{array}$ & $\begin{array}{l}\text { Anogenital } \\
\text { sites only }\end{array}$ \\
\hline NR & 24 & 31 \\
NR Pheni & 8 & 7 \\
Pro- & 20 & 16 \\
Arg- & 8 & 3 \\
Arg- Amac- & 8 & 4 \\
Amac- & 12 & 18 \\
Other & 20 & 21 \\
Total & 100 & 100 \\
\hline
\end{tabular}

Pheni = phenylalanine inhibited; for meanings of other abbreviations see table II.

in isolates from patients with throat and anogenital infections, 20 with throat infections only, and 21 with anogenital infections only (see tables I and III.). Table IV shows the number of strains with arginine and other requirements, 18 in patients with concomitant throat and anogenital infections, 22 in those with throat infections only, and 17 in those with anogenital infections only.

\section{AUXOTYPES AND SUSCEPTIBILITY TO}

ANTIBIOTICS

Table V shows the distribution of the strains from the three groups of non-PPNG strains into categories according to the MICs of the different antibiotics. For convenience only two MICs per antibiotic were chosen. The object was to ascertain whether the distribution of susceptible and moderately susceptible strains and auxotypes differed in the three groups of patients.

TABLE IV No of strains requiring arginine and other substances isolated from both the throat and anogenital sites, the throat only, and anogenital sites only in the same period

\begin{tabular}{lccc}
\hline Auxotype & $\begin{array}{c}\text { Both } \\
\text { sites }\end{array}$ & $\begin{array}{l}\text { Throat } \\
\text { only }\end{array}$ & $\begin{array}{l}\text { Anogenital } \\
\text { sites only }\end{array}$ \\
\hline $\begin{array}{l}\text { Arg- Pro- } \\
\text { Arg- Pro- Meth- }\end{array}$ & 1 & & 3 \\
$\begin{array}{l}\text { Arg- Pro- Amac- } \\
\text { Hyx- Ur- Vit- }\end{array}$ & 1 & 1 & \\
$\begin{array}{l}\text { Arg- } \\
\text { Arg- Amac- }\end{array}$ & 5 & 8 & \\
Arg- Amac- Meth- & 10 & 8 & 4 \\
$\begin{array}{l}\text { Arg- Amac- Hyx- Ur- } \\
\text { Arg- Amac- Hyx- Ur- }\end{array}$ & 1 & 1 & 2 \\
$\begin{array}{l}\text { Meth- } \\
\text { Arg- Amac-Vit- }\end{array}$ & 2 & \\
Arg- Pro- Vit- & & 2 & \\
Arg- Pro- Hyx- Ur- Amac- & & 1 \\
Total & 18 & 22 & 17 \\
\hline
\end{tabular}

Arg- $=$ arginine requiring; Pro- $=$ proline requiring; Meth- = methionine requiring; Amac $-=$ amino acid group requiring; $\mathrm{Hyx}-=$ hypoxanthine requiring; $\mathrm{Ur}-=$ uracil requiring; Vit - = vitamin group requiring.

\section{Susceptibility to penicillin $G$}

About half the 300 isolates were inhibited by 0.06 $\mathrm{IU} / \mathrm{ml}$ and half by $0 \cdot 12-1 \mathrm{IU} / \mathrm{ml}$ penicillin $\mathrm{G}$. The numbers of moderately susceptible strains from the three groups of patients $(58,57$, and 45 respectively), did not differ significantly $\left(\chi^{2}=4 \cdot 2 ; p>0 \cdot 1\right)$. Moderately susceptible strains, however, tended to be found more commonly among isolates from the throat than from anogenital sites. In general there was no striking difference in susceptibility between the two groups of patients with throat infections, though in those with throat infections only the proportion of moderately susceptible strains requiring amino acids and the proportion of susceptible strains requiring proline were relatively high. All throat isolates with the non-requiring auxotype and inhibited by phenylalanine had decreased susceptibility to penicillin. This contrasted with the non-requiring strains that were usually susceptible to $0.06 \mathrm{IU} / \mathrm{ml}$ in all groups. Most strains requiring arginine from all three groups of patients were susceptible, but most strains requiring arginine and the amino acid group from both the groups of patients with throat infections were only moderately susceptible to penicillin.

\section{Susceptibility to tetracycline}

About half the 300 isolates were inhibited by 0.5 $\mu \mathrm{g} / \mathrm{ml}$ and half by $1-4 \mu \mathrm{g} / \mathrm{ml}$ tetracycline. The numbers of moderately susceptible strains in the three groups of patients $(47,52$, and 42 respectively) did not differ significantly $\left(\chi^{2}=2 \cdot 0 ; p>0 \cdot 3\right)$. More moderately susceptible strains were seen in the throat isolates than in isolates from anogenital sites. Two thirds of the strains requiring proline from all grotps of patients were moderately susceptible and most strains requiring the amino acid group were susceptible to $0.5 \mu \mathrm{g} / \mathrm{ml}$ tetracycline.

\section{Susceptibility to erythromycin}

More than two thirds of both groups of patients with throat infections and about $80 \%$ of those with anogenital infections only had strains inhibited by $0.5 \mu \mathrm{g} / \mathrm{ml}$ erythromycin. The rest of the strains from patients in all groups were inhibited by $1-4 \mu \mathrm{g} / \mathrm{ml}$. The numbers of moderately susceptible strains in these groups $(29,29$, and 19 respectively) did not differ significantly $\left(\chi^{2}=3 \cdot 5 ; p>0 \cdot 1\right)$. Most of the proline requiring strains from patients with throat infections and half those from patients with anogenital infections were only moderately susceptible. Most of the non-requiring, nonrequiring and phenylalanine inhibited, arginine requiring, and amino acid group requiring strains were inhibited by $0.5 \mu \mathrm{g} / \mathrm{ml}$ erythromycin. 
TABLE V Auxotypes of 300 strains of $N$ gonorrhoeae and susceptibilities to five antibiotics

\begin{tabular}{|c|c|c|c|c|c|c|c|c|c|c|}
\hline & \multicolumn{10}{|c|}{ No of strains* susceptible and moderately susceptible to: } \\
\hline & \multicolumn{2}{|c|}{$\begin{array}{l}\text { Penicillin } \\
\text { (MICs IU/ml) } \\
\leqslant 0.06 \quad 0.12-I\end{array}$} & \multicolumn{2}{|c|}{$\begin{array}{l}\text { Tetracycline } \\
(M I C s \mu g / m l) \\
\leqslant 0.5 \quad I-4\end{array}$} & \multicolumn{2}{|c|}{$\begin{array}{l}\text { Erythromycin } \\
(M I C s \mu / m l) \\
\leqslant 0.5 \quad I-4\end{array}$} & \multicolumn{2}{|c|}{$\begin{array}{l}\text { Cefuroxime } \\
(M I C s \mu g / m l)\end{array}$} & \multicolumn{2}{|c|}{$\begin{array}{l}\text { Thiamphenicol } \\
\text { (MICs } \mu \mathrm{g} / \mathrm{ml})\end{array}$} \\
\hline \multicolumn{11}{|l|}{ Non-requiring (NR): } \\
\hline Throat \& anogenital sites & $12(+1)$ & 6 & 9 & $9(+1)$ & $17(+1)$ & 1 & $14(+1)$ & 4 & $16(+1)$ & 2 \\
\hline Throat only & $17(+1)$ & 7 & 11 & 13 & 21 & 3 & 18 & 6 & $24(1+1)$ & 0 \\
\hline Anogenital sites only & 20 & 11 & 17 & 14 & 25 & 6 & 27 & 4 & 24 & 7 \\
\hline \multicolumn{11}{|c|}{ NR and phenylalanine inhibited: } \\
\hline Throat \& anogenital sites & 0 & 11 & 3 & 8 & 11 & 0 & 11 & 0 & 11 & 0 \\
\hline Throat only & 0 & 8 & 6 & 2 & 8 & 0 & 8 & 0 & 8 & 0 \\
\hline Anogenital sites only & 3 & 4 & 6 & 4 & 7 & 0 & 6 & 1 & 7 & 0 \\
\hline \multicolumn{11}{|l|}{ Proline requiring: } \\
\hline Throat \& anogenital sites & $6(+1)$ & 15 & $8(+1)$ & 13 & $6(+1)$ & 15 & $5(+1)$ & 16 & $9(+1)$ & 12 \\
\hline Throat only & 12 & 8 & 6 & 14 & 7 & 13 & 9 & 11 & 10 & 10 \\
\hline Anogenital sites only & 4 & 12 & 3 & 10 & 8 & 8 & 4 & 12 & 7 & 9 \\
\hline \multicolumn{11}{|l|}{ Arginine requiring: } \\
\hline Throat \& anogenital sites & 5 & 0 & 4 & 1 & 4 & 1 & 4 & 1 & 1 & 4 \\
\hline Throat only & 7 & 1 & 3 & 5 & 7 & $i$ & 8 & 0 & $i$ & 7 \\
\hline Anogenital sites only & 2 & 1 & 3 & 0 & 2 & 1 & 3 & 0 & i & 2 \\
\hline \multicolumn{11}{|c|}{ Arginine \& amino acids requiring: } \\
\hline Throat \& anogenital sites & 1 & $5(+4)$ & 5 & $1(+4)$ & $4(+3)$ & $2(+1)$ & $3(+3)$ & $3(+1)$ & $5(+2)$ & $1(+2)$ \\
\hline Throat only & 1 & 7 & 4 & 4 & 3 & 5 & 5 & 3 & 5 & 3 \\
\hline Anogenital sites only & 2 & 2 & 2 & 2 & 2 & 2 & 2 & 2 & 3 & 1 \\
\hline \multicolumn{11}{|l|}{ Amino acids requiring: } \\
\hline Throat \& anogenital sites & $9(+1)$ & 12 & $18(+1)$ & 3 & 14 & $7(+1)$ & $11(+1)$ & 10 & $19(+1)$ & 2 \\
\hline Throat only & 2 & 10 & 9 & 3 & 11 & 1 & 6 & 6 & 11 & 1 \\
\hline Anogenital sites only & 11 & 7 & 14 & 4 & 17 & 1 & 12 & 6 & 16 & 2 \\
\hline \multicolumn{11}{|l|}{ Other requirements: } \\
\hline Throat \& anogenital sites & 6 & 5 & 4 & 7 & 10 & 1 & 7 & 4 & 9 & 2 \\
\hline Throat only & 4 & 16 & 9 & 11 & 14 & 6 & 14 & 6 & 13 & 7 \\
\hline Anogenital sites only & 13 & 18 & 13 & 8 & 20 & 1 & 14 & 7 & 16 & 5 \\
\hline \multicolumn{11}{|l|}{ All auxotypes: } \\
\hline Throat \& anogenital sites & 42 & 58 & 53 & 47 & 71 & 29 & 61 & 39 & 75 & 25 \\
\hline Throat only & 43 & 57 & 48 & 52 & 71 & 29 & 68 & 32 & 72 & 28 \\
\hline Anogenital sites only & 55 & 45 & 58 & 42 & 81 & 19 & 68 & 32 & 74 & 26 \\
\hline
\end{tabular}

* No of throat strains in parentheses when their auxotypes differed from those of anogenital strains (see table II).

\section{Susceptibility to cefuroxime}

In each of the three groups of patients about two thirds of the strains were inhibited by $0.03 \mu \mathrm{g} / \mathrm{ml}$ cefuroxime the rest by $0 \cdot 06-0 \cdot 15 \mu \mathrm{g} / \mathrm{ml}$. The numbers of the latter moderately susceptible strains (39, 32, and 32 respectively) did not differ significantly $\left(\chi^{2}=1 \cdot 45 ; p>0 \cdot 3\right)$. Many proline requiring strains were only moderately susceptible, whereas most of non-requiring and phenylalanine inhibited and the arginine requiring isolates were susceptible to $0.03 \mu \mathrm{g} / \mathrm{ml}$ cefuroxime.

\section{Susceptibility to thiamphenicol}

In each of the three groups of patients nearly three quarters of the strains were inhibited by $0.5 \mu \mathrm{g} / \mathrm{ml}$, and the remainder by $1-4 \mu \mathrm{g} / \mathrm{ml}$ thiamphenicol. The numbers of the latter moderately susceptible strains $(25,28$, and 26 respectively) did not differ significantly $\left(\chi^{2}=0 \cdot 24 ; p>0 \cdot 8\right)$. More than half of the strains requiring proline in all groups were only moderately susceptible, as were many arginine requiring strains. Most of the non-requiring and phenylalanine inhibited and amino acid group requiring strains were susceptible to $0.5 \mu \mathrm{g} / \mathrm{ml}$ thiamphenicol.

\section{Susceptibility to spectinomycin}

The strains from all groups of patients were susceptible to $16 \mu \mathrm{g} / \mathrm{ml}$ spectinomycin.

\section{Aminopeptidase activity}

Among the isolates from the throat referred to us as being $N$ gonorrhoeae, nine that fermented glucose but not maltose grew on our defined medium without a mixture of cysteine and cystine. The nine strains showed $\gamma$-glutamylaminopeptidase activity. By meningococcal serotyping (H C Zanen, University of Amsterdam) two strains were shown to belong to $N$ meningitis group $\mathrm{B}$, two to group $\mathrm{C}$, and five were ungroupable.

\section{Discussion}

Most (93 of 100) of the paired cultures from the throat and anogenital sites were identical as far as auxotyping and susceptibility to antibiotics were concerned. Among the seven pairs with differing auxotypes those requiring arginine and the amino acid group predominated in the throat (four isolates) and those requiring proline and other requirements predominated in the anogenital sites (four isolates). 
A low incidence of non-identical strains in paired cultures was also reported by Lind, who found only seven of 198 pairs of strains of $N$ gonorrhoeae from the throat and anogenital areas with different susceptibilities to penicillin. ${ }^{11}$ Noble found strains with different auxotypes from two sites of urogenital infections in six $(8 \cdot 7 \%)$ out of 69 patients. ${ }^{12}$

In this study of three groups of non-PPNG strains (100 isolates from throat and anogenital sites at the same time from the same patient, 100 from the throat only, and 100 isolates from anogenital sites only) the percentages of the predominant auxotypes (nonrequiring, non-requiring and phenylalanine inhibited, proline requiring, and amino acid group requiring) were about the same. The highest incidence of non-requiring strains was found in patients with anogenital infections (see tables I and III). The proportion of arginine requiring strains isolated from the two groups of patients with throat infections was about $20 \%$ and from anogenital sites $17 \%$, although more strains from the latter sites had additional and more complicated requirements (see table IV). Janda et al also reported $20 \%$ arginine requiring isolates from the throat. ${ }^{5}$

The number of strains with decreased susceptibility to antibiotics in the two groups of patients with throat infections did not differ significantly from that in patients with anogenital infections, with only a tendency to more moderate susceptibility in the throat isolates. About half the throat isolates were found to be moderately susceptible to penicillin. This was mainly due to the non-requiring phenylalanine inhibited and the arginine and amino acid group requiring strains and partly due to the proline requiring and amino acid group requiring strains. This diminished sensitivity was found in $45 \%$ of the isolates from patients with anogenital infections only, in whom non-requiring and proline requiring auxotypes predominated. The MIC of tetracycline for about half the strains in the three groups of patients was more than $1 \mu \mathrm{g} / \mathrm{ml}$. The less susceptible strains were found in the proline requiring auxotypes from all groups. Diminished susceptibility to erythromycin and cefuroxime was seen in strains with the proline requiring auxotype. The arginine requiring strains from all groups of patients were generally susceptible to all the antibiotics tested except thiamphenicol. The non-requiring phenylalanine inhibited strains were all susceptible to $0.5 \mu \mathrm{g} / \mathrm{ml}$ thiamphenicol. PPNG strains with this auxotype appeared to have the same susceptibility. The non-requiring and phenylalanine inhibited and proline requiring auxotypes were predominant among the PPNG strains from the throat during this study. They were the most common PPNG strains circulating in Amsterdam at this time. ${ }^{13}$ From our findings it would appear that the types of $N$ gonorrhoeae isolated from the throat are more or less the same as those in general circulation in a specific population at any particular time. This suggests that the difficulty of eradicating $N$ gonorrhoeae from the throat is due more to problems with the site of the organism than to its biological properties.

The misidentification of Neisseria spp from the throat as $N$ gonorrhoeae could be obviated by using the aminopeptidase assay as d'Amato et al did when they found $N$ meningitidis giving negative maltose reactions. ${ }^{14}$

The auxanographic typing of the $N$ gonorrhoeae was made possible by the financial support of the "Praeventiefonds" of the Netherlands. We thank Professor H C Zanen for his comments, Dr H G Ross for clarification of English, Drs G A J de Koning and D Tio and the staff of the STD clinics of Amsterdam, and Mrs W M Maruanaya for typing the manuscript.

\section{References}

1. Stolz E, Schuller J. Gonococcal oro- and nasopharyngeal infection. British Journal of Venereal Diseases 1974;50: 104-8.

2. Bro-Jorgensen A, Jensen T. Gonococcal pharyngeal infections: report of 110 cases. British Journal of Venereal Diseases 1973;49:491-9.

3. Young H, Bain SSR. Neisserial colonisation of the pharynx. British Journal of Venereal Diseases 1983; 59:228-31.

4. Catlin BW, Pace PJ. Nutritional requirements and penicillin susceptibilities of gonococci from pharyngeal and anogenital sites. British Journal of Venereal Diseases 1977;53:299-303.

5. Janda WM, Morello JA, Lerner SA, Bohnoff M. Characteristics of pathogenic Neisseria spp. isolated from homosexual men. J Clin Microbiol 1983; 17:85-91.

6. Noble RC, Parekh MC. Association of auxotypes of Neisseria gonorrhoeae and susceptibility to penicillin G, spectinomycin, tetracycline, cefaclor, cefoxitin and moxalactam. Sex Transm Dis 1983; 10: 18-23.

7. Klingeren B van, Ansink-Schipper MC, Dessens-Kroon M, Woudstra RK, Huikeshoven MH. Relationship between auxotype, plasmid pattern and susceptibility to antibiotics in penicillinase producing Neisseria gonorrhoeae. Antonie van Leewwenhoek (in press)

8. Ansink-Schipper MC, Huikeshoven MH, Woudstra RK, et al. Epidemiology of PPNG infections in Amsterdam: analysis by auxanographic typing and plasmid characterisation. British Journal of Venereal Diseases 1984; 60:23-8.

9. Klingeren $B$ van, Wijngaarden $\mathbf{L J}$ van, Dessens-Kroon $\mathbf{M}$, Embden JDA van. Penicillinase-producing gonococci in the Netherlands in 1981. J Antimicrob Chemother 1983;11:15-20.

10. Hoke C. Vedros NA. Taxonomy of the neisseriae: fatty acid analysis. aminopeptidase activity, and pigment extraction. International Journal of Systematic Bacteriology 1983:32:51-6.

11. Lind I. Activities of the WHO collaborating centre for reference and research in gonococci. Copenhagen. WHO/ VDT RES (ION 82, 1982: 138:5

12. Noble RC. (Characterisation of Neisseria gonorrhoeae from women with simultaneous infections at two sites. British Journal of lienereal Disease's 1980; 56: 3-5.

13. Ansink-Sihipper MIC. Klingeren $B$ van, Huikeshoven $M H$, Woudstra RK. Dessens-kroon M, Wijngaarden LJ van. Epidemiology of PPNGi infections in the Netherlands. Analysis by auxanographic tvping and plasmid identification. British Journal of Venereal Diseases 1984;60:141-6.

14. d'Amato RF, Eriquez LA, Tomfohrde KM, Singerman E. Rapid identification of Neisseria gonorrhoeae and Neisseria meningitidis by using enzymatic profiles. J Clin Microbiol 1978; 7:77-81. 